\title{
Thinking about Crime
}

\author{
Honey Gurbaxani Kalyani* \\ Consultant Orthodontist, India \\ *Corresponding Author: Honey Gurbaxani Kalyani, Consultant Orthodontist, India.
}

Received: June 13, 2019; Published: July 15, 2019

DOI: 10.31080/ASDS.2019.03.0592

\begin{abstract}
The topic of crime finds a place in discussion not only among the legal system but also among the general population. However, street crimes such as eve teasing, thefts, drug dealing and abusing are quite common topics gaining criminal importance. Offensive acts occurring in the professional streams are never in the limelight. In the current paper, a single type of occupational crime is discussed. Medial crime being the concept of interest here, involves a variety of illegal acts being carried out in the field of medicine. Performing surgical interventions at the time where they are not required, prescribing heavy doses of medications, offering or accepting kickbacks, splitting fees, exorbitant charges are some of the offensive acts seen in this profession. However a lack of knowledge of the terminologies like medical offense, negligence or error and also a perspective which overlooks the harm caused to the patients, crime in medicinal field is rarely spoken about. Nevertheless it still continues to be the most harmful type of occupational crime.
\end{abstract}

Keywords: Medical Crime; Medical Negligence; Medical Offense

\section{Introduction}

Medicine and health care is considered as a noble profession all across the globe. However a host of malpractices such as feesplitting, taking or offering kickbacks, price fixing, fraudulent billing and performing unnecessary operations, have popped up in the field by professionals seeking commercial satisfaction [1]. Crime in the medical fraternity is one of the most heinous types of occupational crimes, completely undermining the former's integrity.

To be elaborative, criminals could be in form of pharmacists, doctor himself, laboratory and hospital staff. As for example, pharmacist may hike a price for medications delivered to the patients. The same may be followed by a doctor availing unnecessary services to the patients, deviating from the actual medical condition, often death due to negligence. Hospital staff may use improper or faulty techniques to provide the adjunctive treatment facilities. Unwarranted surgery represents a problem of staggering magnitude in terms of needless pain, suffering, and death, as well as a substantial waste of human and financial resources. In extreme cases, there may be a deliberate exchange of blood/urine samples in the labs, misinterpretation of reports, over dose of radiation exposure, mal handling of blood samples to be transfused or organs to be donated adding to the strata of medical crimes. The worst of the malpractices are done in a mortuary where organs maybe removed and sold off for monetary gains. Autopsies done in a morgue can also be done in an incorrect manner. Medical tourism and insurance agencies also can take a client seeking their help for a ride, charging them exorbitantly with absolutely zero delivery of the service promised. All these activities are ultimately brought to the notice of the jurisdiction pertaining to medical laws and governance which decide the punishment.

The present paper focuses on finding answers to the following two questions:

- What exactly medical negligence is and how appropriately can it be defined

- At what stage of the negligence is it considered offensive and calls for a punishment 


\section{What is medical negligence?}

Various terminologies and definitions used to describe what crime in medicine means, at what stages it can happen and who all could be a part of it, originate in the legal system. A broad terminology like medical error is used which is inclusive of words like medical malpractice, negligence, doctor's fault. These are more or less synonyms and used interchangeably. Rudolf Virchow first mentioned about medical error in 1869 when he took to defining errors in medicine [2]. However the most appropriate and apt term would be medical negligence because errors and indifferent attitude can not only be exhibited by the doctor himself, but also can find roots in the hospital staff, nurses, laboratory assistants, radiology attendants or even the pharmacists [3]. It is also considered as failure of a plan that was meant to execute in a particular way [4]. It can also be considered as the act of omission by the people belonging to the medical community during the course of the treatment which leads to a deviation from the norms resulting into a harm to the patient [5]. However the deviation needs to be an extremely gross one in order to be called as medical negligence [6].

\section{Medical negligence: offense and punishment}

When deciding as to what is considered as an offense in medicine or which crimes call for a punishment, certain criteria need to be taken into consideration5. The patient-doctor relationship tops the list in the selection criteria. A nurse giving a high dose of sedation in cases of emergency to a patient in the intensive care unit leading to fatal outcome or a radiology assistant doing a cardiopulmonary resuscitation on a patient in the casualty resulting in fracture of the ribs often lead to a confusion in terms of describing them as crimes. There is no professional relationship established between the nurse or the radiology assistant with their respective patients; the former only acted according to the emergency. Next follows the actual violation of the standard medical procedures. This is attributed to the fact that uncertainty prevails in the field of medicine literature pertaining to diagnosis, treatment procedures and their outcomes. It was argued that an elaborate explanation of the etiological factors causing a disease, precise diagnostic approach and the possible treatment outcomes can never be accurately described in medical literature [7]. Moreover, a physical or clinical examination of the patient will never be able to give enough information to the physician so as to be hundred percent sure of the future planning. It was also stated that medicine can only achieve status of established science only when the basic laws of health and disease are defined [1].
Lastly, there must be a strong causative factor to find an association between the violation done at the hands of the doctor and the undue effect on the patient. This is explained well by the equivalence theory in criminal law [6]. This theory in based on the concept of sine qua non which explains that a condition can be considered extremely necessary only when the outcome is disastrous. For example, if the neurosurgeon had not performed the surgery, the brain tumor would not have worsened. Clubbed with this theory are the theory of adequate causation and the theory of acting in accordance with regulations [8]. The theory of adequate causation speaks about the conduct of a doctor during a particular procedure and also about the course of events that are expected to be seen. As for example, while giving a mandibular nerve block for the extraction of a lower molar it is expected to attain numbness at the site of block as well as at the tip of tongue. An allergic reaction may trigger at the site of injection considering the sensitivity of the patient which the doctor may otherwise have failed to take prior history of. Though an anticipation of an allergic reaction can be made, it almost never occurs as a result of any fault from the end of the medical professional. Therefore there is no legal causation attached to such a phenomenon. Another example is of a clinical situation where vaccination that has no side effects is being given to a child by the nurse, but in this particular case it triggers an anaphylactic reaction in the patient. This event the nurse could have not foreseen and hence cannot be considered as a heinous intent from his or her end. The theory of acting in accordance with regulations emphasizes on the standard protocols the doctors are expected to follow for a particular medical procedure without considering the outcome for which the procedure is being carried out [6]. For example, if a doctor behaves in a negligent manner with an 80 year old man with pneumonia and does not provide him the standard treatment regimen resulting into his death; it would not make any difference since the patient would have died anyway. Here comes the role of how thoroughly versed the doctor is with the literature of the disease and when to follow the treatment regimens. The ultimate factor that is used to establish criminal liability is an obvious and unjustifiable doctor's negligence1. Criminal law in medicine speaks both about the medical errors as well as medical negligence. If the doctor functions in a manner to deliberately harm, kill or injure the patient by any means, it is not only considered as a medical error, but also a crime beyond punishment. An inattentive, carefree, lenient and an inconsistent approach towards any of the medical procedures would account for medical negligence. As for example 
the doctor knows an additional computed tomography image would be required to study the degree of dislocation of inter vertebral discs in the spine, but manages to proceed with the treatment based on postero anterior view images only. In cases where a blood test should be mandatory to at least diagnose the type of infection, the doctor still chooses to prescribe antibiotics solely based on the symptoms seen as part of physical and clinical examination also is considered as a medical negligence.

\section{Conclusion}

The impact and effects of the application of criminal law in medicine is quite complicated. Complexity lies at each stage of help the medical professionals avail, ranging from the consent taken for the patients to the actual treatment followed and provided to them, manipulation of lab reports and samples, trading of body parts etc. The greatest dilemma ever lies in the question of which type of medical error or negligence is actually offensive and calls for a criminal prosecution. After considering the examples quoted here in the paper, it will be safe to conclude that doctors should not be exempted from the punishment owing to the fact that they are considered as life givers and sometimes as next to God. There is no absolute argument that criminal prosecution should be completely excluded [5]. There are however, arguments that criminal prosecution of doctors should be an exception and not a rule (Sara Hogan 2016). There are also strong arguments to be made that because of the inherently risky nature of medicine, there should be a privileged criminal offence for negligent doctors with lower sentence in comparison to the fundamental offences of causing death or serious bodily harm to another due to negligence.

\section{Bibliography}

1. Sara Hogan. "Medical Crime: Occupational crime at its worst". Sociological Imagination: Western's Undergraduates Sociology Student Journal 5 (2006): 1-7.

2. Brenner. "Beyond the Standard of Care: A New Model to Judge Medical Negligence". Clinical Orthopaedics and Related research 470.5 (2012): 1357-1364.

3. Pandit. "Medical negligence: Criminal prosecution of medical professionals, importance of medical evidence". Indian Journal of Urology 25.3 (2009): 379-83

4. Kohn. Principles of criminal law, seventh edition (2000).

5. Sonny Bal. "An introduction to medical malpractise". Clinical Orthopaedics and Related Research 467.2 (2009): 339-347.
6. Grunsven. "Medical Malpractice or Criminal Mistake - An Analysis of Past and Current Criminal Prosecutions for Clinical Mistakes and Fatal Errors". DePaul Journal of Health Care Law 2 (1997): 1-54.

7. Helmer. "On the Epistemology of Inexact Sciences". Management Science 6 (1959): 25-52.

8. Dežman. "Zakon o pacientovih pravicah in njegov kazensko pravni vidik". In: Rijavec, V., Reberšek Gorišek. Faculty of Law of University of Maribor (2010): 375-388.

\section{Volume 3 Issue 8 August 2019}

(C) All rights are reserved by Honey Gurbaxani Kalyani. 